\title{
Prevalence and Epidemiological Profile of Accidents with Exposure to Blood Among Health Professionals in Two Hospitals in the North of Togo
}

\author{
Wasungu Bassokla Ditorguena ${ }^{1,2, *}$, Djalogue Prisca ${ }^{3}$, Agbobli Yawo Apelete', \\ Dadjo Soukouna Francis ${ }^{1}$, Sidy Dia ${ }^{4}$, Mame Coumba Gaye Fall ${ }^{4}$, Ekouevi Koumavi Didier ${ }^{5}$, \\ Wognin Sangah $^{6}$, Ndiaye Mor ${ }^{4}$, Bonny Jean-Sylvain ${ }^{6}$, Sow Mamadou Lamine ${ }^{4}$ \\ ${ }^{1}$ Department of Medicine and Specialties, University of Lome, Lome, Togo \\ ${ }^{2}$ Occupational Health Research and Expertise Unit, Occupational Health Consulting, Lome, Togo \\ ${ }^{3}$ Department of Medicine and Specialties, University of Kara, Kara, Togo \\ ${ }^{4}$ Faculty of Medicine and Odonto Stomatology, University Cheikh Anta Diop, Dakar, Senegal \\ ${ }^{5}$ Department of Epidemiology and Public Health, University of Lome, Lome, Togo \\ ${ }^{6}$ Training and Research Unit in Medical Sciences, University of Felix Houphouet Boigny, Abidjan, Ivory Coast
}

Email address:

jpwasungu@gmail.com (W. B. Ditorguena)

*Corresponding author

To cite this article:

Wasungu Bassokla Ditorguena, Djalogue Prisca, Agbobli Yawo Apelete, Dadjo Soukouna Francis, Sidy Dia, Mame Coumba Gaye Fall, Ekouevi Koumavi Didier, Wognin Sangah, Ndiaye Mor, Bonny Jean-Sylvain, Sow Mamadou Lamine. Prevalence and Epidemiological Profile of Accidents with Exposure to Blood Among Health Professionals in Two Hospitals in the North of Togo. Journal of Health and Environmental Research. Special Issue: Lack of Education in the Field of Health and Environment in Undeveloped Countries.

Vol. 5, No. 4, 2019, pp. 95-100. doi: 10.11648/j.jher.20190504.11

Received: June 24, 2019; Accepted: October 14, 2019; Published: December 5, 2019

\begin{abstract}
Accidents with exposure to blood (AEBs) remain a reality in healthcare settings and are, by their frequency, a major concern for health professionals. This study was conducted to evaluate the prevalence of AEBs history, to identify the types, circumstances and mechanisms of occurrence and to describe the practices of health professionals with respect to AEBs. We conducted a descriptive cross-sectional study over a period of two (02) months (September-October 2018) in two hospitals, the Kara's teaching hospital and Kara's regional hospital, both located in the north, 418 kilometers from Lomé, economic capital of Togo. The study population was represented by health professionals practicing in the district pediatrics, surgery, gynecology-obstetrics, emergencies and laboratories of the said centers. Were included in the study health professionals presents and available in the above-mentioned services at the time of the survey. Hospital staff not directly involved in patient care (administrative, mortuary staff, vigils, pharmacy salesmen) were excluded from the study. This research was a descriptive-analytical technique using interviews and questionnaires anonymized and adapted in such a way that it meets our objectives. Methods of data analysis were made using the Sphinx V5 software version 5.1.0.2. The Chisquare statistical test was used to compare the proportions with a significance threshold of $5 \%$. The prevalence of AEBs was estimated at $67.6 \%$. The results show that AEBs were frequent among men compared to women $(72.7 \%$ vs $58.3 \%)$, without significant difference. Age, occupational qualification and seniority in the medical profession were significantly associated to AEBs. The most common mechanism of occurrence was the skin break (89.1\%). The equipment or sharp objects handled at the time of the accident were a hollow needle (58.8\%), and the most incriminated body fluid was blood (71.7\%). AEBs are a reality in health care in Togo with a very high prevalence and concern daily all socio-professional categories especially the nurses and the midwives during the care tasks. Exposure is roughly daily, however, the amount of vaccination coverage in these two hospitals is low. In addition, for health care workers to some dangerous actions, such as disposal of used needles, lack of attention to wearing PPE will be accepted in certain circumstances without risk, it is observed.
\end{abstract}


Keywords: Accident with Exposure to Blood, Prevalence, Healthcare, Togo

\section{Introduction}

Accidents with exposure to blood (AEBs) remain a reality in healthcare settings and are, by their frequency, a major concern for health professionals [1-4]. In 2002, in its World Health Report, WHO estimated that of the world's 35 million health care providers, 3 million people each year had percutaneous exposure to pathogens transmitted by the disease, two million for $\mathrm{HBV}, 0.9$ million for $\mathrm{HCV}$ and 170,000 for HIV [5-6]. Defined as accidental contact with blood or biological fluid contaminated with blood when biting with a needle, cutting with a sharp object or contact with blood or contaminated fluid on a wound, an injured skin or a mucous membrane [7], AEBs exposes the healthcare professionals, as part of their daily activities to the risk of contamination by a variety of germs [8], the most formidable of which are the hepatitis $\mathrm{B}$ viruses, $\mathrm{C}$ and HIV [9-13]. In developed countries, while the incidence of AEBs is decreasing because of the epidemiological studies that have identified the contributing factors and planning prevention [14-15], this is not the case in our countries developing countries, particularly in Togo, where sometimes unsuitable working conditions and the diversity of tasks performed by healthcare professionals make it difficult to identify a particularly risky function of AEBs [16] and Biological risk management is virtually nonexistent in most health facilities. In this context, the role of the occupational health physician in the monitoring of work places and conditions is essential in order to contribute to the identification of risk factors, the compilation of statistics on occupational accidents and the development of a prevention plan adapted to the workplace [17]. The purpose of this work is to provide a database that can be used as a support for planning the prevention of AEBs and other body fluids in the health care setting. The objectives of this study are to estimate the prevalence of AEBs history, to identify the types, circumstances and mechanisms of occurrence of AEBs and to describe the practices of health professionals with respect to AEBs.

\section{Materials and Methods}

We conducted a descriptive cross-sectional study over a period of two (02) months (September-October 2018) in two hospitals, the Kara's teaching hospital and Kara's regional hospital, both located in the north, 418 kilometers from Lomé, the capital of Togo. The study population was represented by health professionals practicing in the departments of medicine, pediatrics, surgery, gynecologyobstetrics, emergencies and laboratories of the said centers. This population was made up of medical staff (doctors and surgeons of various specialties) and paramedical staff (nurses, midwives, laboratory technicians, nursing assistants). Were included in the study health professionals presents and available in the above-mentioned services at the time of the survey. Hospital staff not directly involved in patient care (administrative, mortuary staff, vigils, pharmacy salesmen) were excluded from the study.

The survey support is an individual questionnary, anonymized and adapted in such a way that it meets our objectives. It includes socio-demographic and occupational data (age, sex, professional qualification, seniority in the medical profession); the existence of a history of AEBs, the number of accidents that occurred; the AEBs profile (current task, mechanism and type, material or sharp object, contaminant involved, evaluation of biosafety and AEBs prevention practices, and evaluation of hospital staff practices following an AEBs. The questionnary was given to each of the interviewees after an explanation of the objectives of the study, which had a period of three (03) days to fill it out and then we look for the answer. Data analysis were made using the Sphinx V5 software version 5.1.0.2. The Chi-square statistical test was used to compare the proportions with a significance threshold of $5 \%$.

\section{Results}

\subsection{General Information}

Out of 181 professionals we met, 136 agents filled out our questionnaire (a participation rate of $75.1 \%$ ). The average age of the respondents is $39.59 \pm 8.45$ years, with a high representation of the 35-45 age group (44.1\%) and a male predominance $(64.7 \%)$. The responding professionals had less than 5 years of seniority in $17.6 \%$ and more than 10 years in $48.5 \%$. All professional qualifications were represented among respondents: nurses (55.9\%); Doctors and surgeons (4.4\%); midwives (11.8\%); nursing assistants $(19.1 \%)$ and laboratory technicians $(8.8 \%)$.

\subsection{Prevalence of Accidents with Exposure to Blood}

Of the 136 respondents, 92 professionals reported a history of AEB, a prevalence of $67.6 \%$. Of the victims of AEBs, 32 $(34.8 \%)$ reported a single accident and $28(30.4 \%)$ reported at least 3 accidents.

AEBs antecedents were common among men compared to women $(72.7 \%$ vs. $58.3 \%)$, with no significant difference. By contrast, age, professional qualification and seniority in the medical profession were significantly associated with the history of BEA. Table 1 summarizes the prevalence of AEBs by demographic and socio-occupational characteristics. 
Table 1. Prevalence of AEBs by demographic and socioprofessional characteristics.

\begin{tabular}{|c|c|c|c|c|}
\hline & $\mathbf{N}$ & N AEBs & $\%$ & $\mathbf{p}$ \\
\hline \multicolumn{5}{|l|}{ Age } \\
\hline$<35$ years & 34 & 14 & 41,2 & \multirow{2}{*}{$\mathrm{p}<0.001$} \\
\hline$>35$ years & 102 & 78 & 76,5 & \\
\hline \multicolumn{5}{|l|}{ Sex } \\
\hline Males & 88 & 64 & 72,7 & \multirow{2}{*}{ NS } \\
\hline Females & 48 & 28 & 58,3 & \\
\hline \multicolumn{5}{|l|}{ Professional qualification } \\
\hline Doctors and surgeons & 6 & 2 & 33,3 & \multirow{5}{*}{$\mathrm{p}=0.037$} \\
\hline Nurses & 76 & 58 & 76.3 & \\
\hline Midwives & 16 & 12 & 75 & \\
\hline Laboratory technicians & 12 & 6 & 50 & \\
\hline Carers & 26 & 14 & 53,8 & \\
\hline \multicolumn{5}{|c|}{ Seniority in the medical profession (years) } \\
\hline$<5$ & 24 & 8 & 33,3 & \multirow{3}{*}{$\mathrm{p}=0.004$} \\
\hline $5-10$ & 46 & 34 & 73,9 & \\
\hline$>10$ & 66 & 50 & 75,8 & \\
\hline
\end{tabular}

\subsection{Profile of Accidents with Exposure to Blood}

It has been reported on average 2.37 AEBs per victim. The majority of these AEBs occurred during nursing and surgical procedures in $41.3 \%$ and $23.9 \%$ respectively. The most common mechanism of occurrence was skin break-in $(89.1 \%)$, of which $71.7 \%$ were stings. The equipment or sharp objects handled at the time of the accident were a hollow needle $(58.8 \%)$, a full needle $(13 \%)$ and a scalpel $(13 \%)$. The most incriminated body fluid was blood (71.7\%). Other contaminants such as biomedical waste and soiled lingerie were reported in $8.7 \%$ and $2.2 \%$ of situations respectively (Table 2).

Table 2. Profile of Accidents with Exposure to Blood $(n=92)$.

\begin{tabular}{|c|c|c|c|}
\hline & $\mathbf{n}$ & $\%$ & $\mathbf{p}$ \\
\hline \multicolumn{4}{|l|}{ Tasks in progress } \\
\hline Medical care & 38 & 41,3 & \multirow{5}{*}{$\mathrm{p}<0.001$} \\
\hline Chirurgical act & 22 & 23,9 & \\
\hline Handling of blood products & 12 & 13 & \\
\hline Intervention on parturient or newborn & 8 & 8,7 & \\
\hline Transport of waste, storage & 12 & 13 & \\
\hline \multicolumn{4}{|l|}{ Mechanism of occurrence } \\
\hline Skin effraction & 82 & 89,1 & \multirow{3}{*}{$\mathrm{p}<0.001$} \\
\hline Splash & 10 & 10,9 & \\
\hline \multicolumn{3}{|l|}{ Type of $A E B s$} & \\
\hline Needles sticks & 66 & 71,7 & \multirow{3}{*}{$\mathrm{p}<0.001$} \\
\hline Cut & 16 & 17,4 & \\
\hline Spash & 10 & 10,9 & \\
\hline \multicolumn{4}{|l|}{ Sharp material or manipulated objects } \\
\hline Full needle & 12 & 13 & \multirow{6}{*}{$\mathrm{p}=0.01$} \\
\hline Hollow needle & 54 & 58,7 & \\
\hline Surgical or dental instrument & 2 & 2,2 & \\
\hline Bistoury & 12 & 13 & \\
\hline Laboratory materials & 4 & 4,3 & \\
\hline Not applicable (projections) & 8 & 8,7 & \\
\hline \multicolumn{4}{|l|}{ Contaminated products under investigation } \\
\hline Blood & 66 & 71,7 & \multirow{4}{*}{$\mathrm{p}<0.001$} \\
\hline Other biological fluids contaminated by blood & 16 & 17,4 & \\
\hline Biomedical wastes & 8 & 8,7 & \\
\hline Dirty Lingerie & 2 & 2,2 & \\
\hline
\end{tabular}

\subsection{Prevention Practices for Biological Hazards and AEBs}

a. The victims in $63 \%$ of cases were not up to date with their vaccination against $\mathrm{HBV}$ and $30.4 \%$ did not know their HIV status.

b. In addition to the work coat, other personal protective equipment (gown, gloves, glasses, apron) were only available in $71.7 \%$ of cases. When these were available, they were consistently worn in only $43.5 \%$ of cases.

c. In the wake of the AEBs; $84.8 \%$ had immediately stopped the current task, $6.5 \%$ had bled the injured party. The cleaning of the exposed part was carried out by $87 \%$ of the victims of which $28.3 \%$ with simple water, $47.8 \%$ with soap and $10.9 \%$ with alcohol. Disinfection of the wound followed cleaning in only $65.2 \%$ of cases. 


\section{Discussion}

\subsection{Prevalence}

The AEBs are very common in health care settings and pose a health and safety problem in developing countries, particularly in Africa, because of the danger of infectious diseases [1]. The major concern of these AEBs is that of the transmission of hepatitis $\mathrm{B}$ and $\mathrm{C}$ viruses and AIDS to health care workers who are exposed to it during the multiple tasks they perform. In our study, the prevalence of AEBs antecedents was estimated at $67.6 \%$. Our data are close to those of Patassi A in Togo in 2003, which reported $77.8 \%$ on all five hospitals [17], while Kara-Peketi K reported in 2011 prevalences of $59.6 \%$ and $62,3 \%$ respectively in the northern region (same region as the present study) and at the national level [18]. Other authors have also found in their respective series, high prevalences [19-22]. This observation could be explained mainly in our context by the absence of a real occupational risk management system in general and particularly the risk of infection in most public and private health facilities. The inappropriate working conditions (high workload, emergency work, difficult tasks) [23], as well as insufficient knowledge of several aspects of standard precautions and inappropriate or even dangerous practices related to infectious risk reported in the health care setting by some authors could also be mentioned as explanatory factors [22, 24-26].

In our series AEBs were more frequent among men without any significant difference, comparable to the results reported by Zannou et al in Benin [27]. On the other hand, in his series, Kara-Peketi in Togo [18] found a significantly higher frequency of AEBs among women, which is also reported by other authors $[23,28]$. The prevalence of AEBs by professional qualification was highest among the nurses and the midwives, the same observation reported by several authors [23, 27, 29-32], this being explained by the nurses by the heavy workload and performing care procedures most of which are at risk (intramuscular or intravenous injections, blood sampling, stitches or wound dressings). In the same instance, Yassi A and McGill M [33] had previously reported that nurses, and especially nursing students, were at the highest risk of needle sticks, thus making this occupational group the most at risk.

\subsection{Profile of Accidents with Exposure to Blood}

Nursing had been reported in $41.3 \%$ in the occurrence of the AEBs and in $89.1 \%$ of cases it was a skin break-in. The same observations were made by Zannou and al in Benin who reported manipulation of blood products, intravenous and intramuscular injections as a task performed at the time of the accident. AEBs by needles sticks were the most common type in our series at $71.7 \%$, this is not a particularity in our context as almost all studies report similar findings [16, 18, 23, 27, 34-36]. However, needles sticks are closely linked to the notion of AEBs, we could dissociate needles sticks by care acts from those emanating from practices at risk in the event of non-compliance with universal precautions (recapping, re-boring used needles) and those related to the management of health care waste (picking up dirty stained objects) as reported by some authors [21, 23, 27, 37-41]. Beside accidents with exposure to blood occurring by stings, it should also be noted as highlighted by Kara-Peketi [18], the particular situations of projections of liquids of which the midwives are victims and in relation to the variety of tasks performed in the delivery room. To prevent this type of AEBs, it is possible as recommended by Jagger et al. [42] to change the design of needles and other sharp instruments to prevent a significant proportion of percutaneous exposures. There should be a fixed barrier between the hands and the needle after use. Any security system should be built into the device and its design should be simple and require little or no training. Despite the almost universal threat of hepatitis B virus to health care workers, especially in endemic African countries, low immunization coverage against viral hepatitis B has been found in the order of $37 \%$. Indeed, $63 \%$ of AEBs victims were not up to date with their vaccination against $\mathrm{HVB}$. This situation could be likely to increase the risk of contamination following an Accident with exposure to blood if we take into account the prevalence of HVB infection (estimated at $10.87 \%$ in the general population [41], type of accident such as accidental stings (more frequent) and transmission rate for $\mathrm{HBV}$ ranging from 6 to $45 \%$ [18]. This could be explained by the fact that in our context, the viral hepatitis B control programs, which are based on the global health sector strategy against viral hepatitis [43], are still lacking. Regardless of these programs, the culture of workplace prevention, especially in the health care setting, is not sufficiently developed, and it should be kept in mind that unvaccinated health care staff would not only be exposed but could also be a potential source of contamination to those around them or to patients as part of chronic carriage as reported by Grob et al. [44]. If preventive measures are taken with an accent for personal protection, it appears from our data, that they are still insufficient insofar as this equipment would be available at only $70 \%$ especially for gloves, other equipment such as bibs, glasses and safety shoes are rarer [18]. It is also noted that personal protective equipment (PPE) was systematically carried only in $43.5 \%$ of cases, indicating a risk-taking by staff to increase exposure to blood or other body fluids, where the need to define protocols or procedures for care in addition to sensitization. The immediate actions to be carried out following an AEB are insufficiently mastered by our victims since only $84.8 \%$ had immediately interrupted the task in progress and $65.2 \%$ had correctly executed the emergency actions following an AEB including the cleaning of the wound followed by disinfection by a suitable solution. It is therefore essential, on the one hand, to set up and then follow the instructions and procedures in case of $\mathrm{AEB}$, and on the other hand to periodically organize simulations to evaluate staff practices to ensure mastery of these procedures. 


\section{Conclusion and Suggestions}

The accidents with exposure to blood in health care in Togo remain a reality with a very high prevalence and concern daily all socio-professional categories especially the nurses and the midwives during the care tasks. The needle sticks and the splashes are the most common types of AEB involving blood manipulation most often. Despite this almost daily exposure, it is noted a low vaccination coverage, however mandatory for health care staff as well as some risky practices such as recapping used needles, neglect of wearing PPE under certain circumstances perceived as riskfree.

According to these results, it appears necessary to establish and implement a prevention plan in a healthcare setting:

a. define a policy to combat occupational hazards with a focus on biological risks,

b. identify and evaluate exposure situations;

c. define procedures for the secure realization of certain tasks;

d. develop the culture of prevention through awareness campaigns and talks;

e. put in place instructions to follow in case of AEB;

f. set up a vaccination strategy for health care staff from health sciences training schools.

g. make known and apply the general hygiene precautions (standard precautions) as well as the supply (and use) of protective equipment

\section{Conflict of Interest Statement}

The authors declare that they have no competing interests.

\section{Acknowledgements}

Our thanks to Occupational Health Unit for Research and Expertise for their financial support in the realisation of this study.

Our thanks to Dr. WASUNGU Isidore for his help to translate this manuscript.

\section{References}

[1] A. Yassi, LJ. Warshaw. Health care: nature and problems of health. In: Stellman JM, Virot A, editors. [Les soins de santé: nature et problèmes de santé. In: Stellman JM, Virot A, editors.] Encyclopedia of safety and health at the work.3rd éd French, translation of the 4th English edition. Geneva; 2002, volume 3, 97: 2-10.

[2] LS. Martin, RJ. Mullan, DM. Bell. Prevention of the transmission of pathogenic agents per blood way in work environment. In: Stellman JM, Virot A, editors. Encyclopedia of safety and health at the work. 3rd éd French, translation of the 4th English edition. Geneva; 2002, volume 3, 97: 44-9.

[3] EB. Guterrez, MH. Lopez, MA. Shikanai Yasuda. Accidental exposure to biological material in healthcare workers at a university hospital: Evaluation and follow-up of 404 cases. Scandinavian Journal of Infectious Diseases 2005; 37: 295-300.
[4] F. Lot. Monitoring of professional contaminations by the VIH, the VHC and the VHB among health care professionals. Situation at December 31, 2007. http:// invs.sante.fr/ publications/ lepointfin2007, pdf.

[5] World Health Organization. The word health report 2002: reducing risks, promoting health life. World Health Organization, Geneva: p. 74.

[6] A. Pruss-Ustun, E. Rapiti, Y. Hutin. Estimation of the global burden of disease attributable to contaminated sharps injuries among health-care workers. Am J Ind Med 2005; 48 (6): 482-90.

[7] A. Cantineau, G. Brauer, V. Deiss, N. Guillet, MT. Hecht. Health care strategy. Accidents with exposure to blood prevention and action-formation. Care 2002; 671: 42-4.

[8] A. Tarantola, D. Abiteboul, A. Rochine. Infection risks following accidental exposure to blood or body fluids in health care workers: a review of pathogens transmitted in published cases. Am J Infect control 2006; 34: 365-75.

[9] Centers for Disease Control. Case-control study of H.I.V. seroconversion in health-care workers after percutaneous exposure to H.I.V.-infected blood-France, United Kingdom and United States, January 988 August 1994. MMWR 1995; 41: 823-5 Traduction dans le BEH 1996; 18: 81-82.

[10] D. Sicard. Occupational HIV infection risk for health care professionals. Conc Med 1992; 114 (17): 1491-6.

[11] M. Domard, D. Abiteboul. Infectious risks analyzed by occupational sectors. Health care Professionals. Arch Mal Prof 1996; 57 (3): 312-7.

[12] F. Lot, AC. De Benoist, D. Abiteboul. Occupational Infectious by HIV among health care professionals in France. Point at 30 juin 1998. BEH 1999; 18: 69-70

[13] F. Lot, D. Abiteboul. Occupational HIV and HCV infections in France among health workers. BEH 1999; 44: 193-1940.

[14] Circular DGS/DH/DRT/DSS n ${ }^{\circ} 98 / 228,1998$. Recommendations for the implementation of antiretroviral treatment after exposure to the risk of HIV transmission.

[15] Circular DGS/DH $n^{\circ} 98 / 249$ of the $20^{\text {th }}$ April 1998 on the prevention of the transmission of infectious agents carried by blood or biological fluids during care in health institutions. BEH 1998; 25: 107-11.

[16] S. Doumbia, E. Bouvet, J. Diarra, F. Mentre, A. Rocaline, A. Tarantola. Predictive factors of accidents with blood exposure occurring at Treichville University Hospital (Abidjan, Ivory Coast). In: Book of Abstracts, XXII International Conference on AIDS and STDs in Africa, 2001; 12 BT3-1: 221.

[17] A. Patassi, TN. Mangbassim. Accidents with exposure to blood among healthcare workers in five hospitals in Togo. Thesis for the graduation of the diploma of higher health technician. University of Lomé, 2003.

[18] K. Kara-Pékéti, H. Magnang, J-S. Bonny, H. Robin, P. Frimat. Prevalence of occupational exposure to blood among healthcare workers in Togo (Africa). Arch. Mal. Prof. Env. 2011; 72: 363-369.

[19] K. Djeriri, R. Charof, H. Laurichess and al. Occupational risk for blood exposure and staff behaviour in a cross-sectional study in 3 Moroccan health care centers. Med Mal Infect 2005; 35 (7-8): 396-401. 
[20] B. Shariati, A. Shahidzadeh-Mahani, T. Oveysi and al. Accidental exposure to blood in medical interns of Teheran University of Medical Sciences. J Occup Health 2007; 49 (6): $317-21$.

[21] O. Laraqui, S. Laraqui, S. Laraqui, S. Laraqui, D. Tripodi, LC. Ouazzani, A. Caubet, C. Verger, CEH. Laraqui. Evaluation of knowledge, attitudes and practices on viral hepatitis B and C in healthcare settings in Morocco. Public Health 2009, 21 (3): 271-286.

[22] SP. Eholie, E. Ehui, BY. Yebouet-Kouame, BP. Simo, A. Tanon, C. Coulibaly-Dacoury, A. Kakou, E. Bissagnene, A. Kadio. Analysis of the practices and knowledge of healthcare workers on accidents with exposure to blood in Abidjan (Ivory Coast). Med Mal Infect 2002; 32: 359-68.

[23] Mr. Ndiaye, comic book. Cissokho, ML. Sow. Accidents with exposure to blood at the Fann National Hospital in Dakar (Senegal). Camip 2011-1, 10p, pdf. Available online: http://www.camip.info/etudes-et-recherches/numerosprecedents/2011/Camip-2011-1/les-accidents-avec-expositionau/Resume,2123?\&var_recherche=ndiaye. "(Accessed on November 12, 2018.

[24] NM. Bambenongama, JL. Likwela. Knowledge, attitudes and practices of health professionals regarding standard precautions in hospitals. Public Health 2013; 25 (5): 663-73.

[25] F. Mérat, F. Trillaud, S. Mérat, S. Deschamps. Incidence of accidents with exposure to blood in an army training hospital. Arch. Bad. Prof. 2004; 65 (4): 335-39.

[26] M. Bouhlel, S. El Guedri, AB. Afia, S. Mlayah, I. Kacem, M. Maoua, A. Brahem, H. Kalboussi, O. El Maalel, S. Chatti, N. Mrizek. Accidents with exposure to blood among young physicians: frequency and risk factors. Arch. Bad. Prof. Env. 2018; 79: 221-233.

[27] DM. Zannou, G. Adè, F. Houngbè, SP. Fanou, B. Fayomi. Epidemiological factors related to accidents with exposure to blood in Cotonou hospitals (Benin). Black African Medicine 2006; 53 (7): 414-18.

[28] I. Sellami, M. Hajjaji, Z. Charmi, A. Kchaou, N. Kotti, KJ Hammami, ML. Masmoudi. Causes of under-reporting of accidents with exposure to blood. Arch. Mal. Prof. Env. 2018; 79: 221-33.

[29] B. Gumodoka, I. Favot, ZA. Berege, WMV. Dolmans. Occupational exposure to HIV infection among health care workers in Mwanza region in Tanzania. WHO Bull 1997; (75): 133-40.

[30] D. Abiteboul, F. Lamontagne, I. Lolom, A. Tarantola, JM. Deschamps, E. Bouvet. Incidence of blood-exposure accidents among nurses in metropolitan France 1990-2000: results of a multicentric survey in 32 hospitals. Bull Epid Hebdo 2002; (51): 256-9.

[31] WL. Boal, JK. Leiss, JM. Ratcliffe, S. Sousa, JT. Lyden, J. Li, J. Jagger. The national study to prevent blood exposure in paramedics: rates of exposure to blood. Int Arch Occup Environ Health 2010; 83: 191-9.

[32] LH. Aiken, DM. Sloane, JL. Klocinski. Hospital occupational exposure to blood: prospective, retrospective and institutional reports. Am Public Health 1997; 87: 103-7.

[33] A. Yassi, M. McGill. Determinants of blood and body fluid exposure in a large teaching hospital: Hazards of the intermittent intravenous procedure. American Journal of Infection Control 1991; 19 (3): 129-35.

[34] EC. Consten, JJ. Van Lanschot, PC. Henny, JG. Tinnemans, JT. Van Der Meer. A prospective study on the risk of exposure to HIV during surgery in Zambia. AIDS 1995; 9: 585-8.

[35] D. Abiteboul, D. Antona, JM. Deschamps, E. Bouvet. GERES, procedures at risk of blood exposure for nurses: surveillance and evolution from 1990 to 1992 in 10 hospitals. BEH 1993; 43: 195-6.

[36] I. El Amri, W. Allouche, B. Benali, A. El Kholti. Blood exposure accidents: biological risk assessment of hemodialysis caregivers. Arch. Bad. Prof. Env 2016; 77: 5456.

[37] CH. Laraqui, D. Tripodi, A. Rahhali, M. Bichara, S. Laraqui, M. Zahraoui $\mathrm{M}$ and al. Knowledge, practice, and behavior of health care workers confronted to AIDS and the occupational risk of HIV transmission in Morocco. Méd Mal Infect 2002; 32: $307-314$.

[38] S. Pungpapong, P. Phanuphak, K. Pungpapong, K. Ruxrungtham. The risk of occupational HIV exposure among Thai health care workers. Southeast Asian J Trop Med Public Health 1999; 30 (3): 496-503.

[39] M-A. Denis, G. Poyard, A. Saury, MF. Forissier, O. Robert, C. Volckmann et al. Under-reporting blood exposure accidents in a university hospital. Arch. Mal. Prof Masson 1998; 59 (4): 242-248.

[40] GERES report. Accidents with exposure to blood and risk of transmission. Knowledge Review, May 1997: 1-47.

[41] A. Bagny, O. Bouglouga, M. Djibril, A. Lawson, LY. Kaaga, HD. Sama, A. Balaka, D. Redah. Knowledge, attitudes and practices of health care professionals on the risk of transmission of viral hepatitis $\mathrm{B}$ and $\mathrm{C}$ in hospitals in Togo. Tropical Medicine and Health 2013; 23: 300-303.

[42] J. Jagger, E. H Hunt, J. Brand-Elnaggar, R. D. Pearson. Rates of needle-stick injury caused by various devices in a university hospital. New England Journal of Medicine 1988; 319 (5): $284-8$.

[43] WHO. Global health sector strategy against viral hepatitis 2016-2021, towards the elimination of viral hepatitis. June 2016, 53p, pdf.

[44] PJ. Grob, B. Bischof, F. Naeff. Cluster of hepatitis B transmitted by a physician. The Lancet 1981; 2 (8257): 121820. 